Discussion: Individuals born in cities and winter are at increased risk of schizophrenia. Moreover, the city birth effect seems to be modified by the season of birth. City birth did not increase the risk of schizophrenia among those born in summer, but was associated with a $21 \%$ increase among the winter born. The confirmation of our predictions suggests that adverse events at or before birth are at least partly responsible for the association between urban upbringing and increased risk of schizo- phrenia found in the recent Swedish cohort study. ${ }^{1}$

We thank the Regional Health Authorities for providing Mental Health Enquiry data, and the Office of Population Censuses and Surveys for providing population data. We are grateful to the Psychiatry Research Trust and the Wellcome Trust (P,S,). This was also supported in part by a Wellcome Training Fellowship in Clinical Epidemiology (NT)

1 Lewis D, David A, Andréasson S, Allebeck P. Schizophrenia and city life. Lancet 1992;340:137-40.

2 Hare E. Temporal factors and trends, including birth seasonality and the viral hypothesis. In: Nasrallah HA, ed. Handbook of schizophrenia, Vol 3. Amsterdam: Elsevier, 1988

\title{
Insulin dependent diabetes mellitus: incidence in childhood in Belgrade 1982-92
}

\section{Institute of \\ Epidemiology, School of Medicine, Belgrade University, \\ Višegradska 26, 11000 \\ Belgrade, Yugoslavia HD Vlajinac \\ BM Bojović \\ SB Šipetić \\ BJ Adanja \\ MS Jarebinski}

University Children's Hospital, Belgrade

SZ Radmanović

Mother and Child Institute, Belgrade DS Zdravković

\section{Correspondence to:}

Dr H Vlajinac.

Accepted for publication June 1994

$(\mp$ Epidemiol Community Health 1995;49:107-8)
Hristina D Vlajinac, Božidar M Bojović, Sandra B Šipetić, Benko J Adanja, Mirjana S Jarebinski, Slobodan Z Radmanović, Dragan S Zdravković

A retrospective technique was used to register all newly diagnosed cases of insulin dependent diabetes mellitus (IDDM) in Belgrade children 0-14 years of age, between 1982 and 1992 . Two independent sources of data were used: patients' records from hospitals where the disease was diagnosed (according to WHO criteria $^{1}$ ) and the population based register. To establish the completeness of ascertainment the capture/recapture method was used. ${ }^{2}$

For calculation of yearly incidence rates, the population denominator data were obtained from the 1981 and 1991 national census data with interpolation. The incidence was standardised by the direct method using the world population as the standard. The $95 \%$ confidence intervals were calculated assuming a Poisson distribution. The significance of seasonal variation was analysed by an ordinary $\chi^{2}$ test.

Results: The ascertainment probability for the whole study period was $90.05 \%$, ranging from $74 \cdot 04 \%$ to $98 \cdot 74 \%$. Between 1982 and 1992 , the mean, annual, age adjusted incidence rates of IDDM (per 100000) were $7 \cdot 3$ for boys, $8 \cdot 1$

Incidence rates (95\% confidence interval(CI)) (per 100000) of insulin dependent diabetes mellitus in Belgrade children 0-14 years in relation to sex, average for 1982-92

\begin{tabular}{|c|c|c|c|c|c|}
\hline & \multicolumn{3}{|c|}{ Age group (y) } & \multirow{2}{*}{$\begin{array}{l}\text { Crude } \\
\text { rate } \\
0-14\end{array}$} & \multirow{2}{*}{$\begin{array}{l}\text { Age adjusted } \\
\text { rate } \\
0-14\end{array}$} \\
\hline & $0-4$ & $5-9$ & $10-14$ & & \\
\hline $\begin{array}{l}\text { Boys } \\
\text { Cases (no) } \\
\text { Population } \\
\text { Incidence rate } \\
(95 \% \text { CI) }\end{array}$ & $\begin{array}{l}24 \\
47 \cdot 574 \\
4 \cdot 6 \\
(2 \cdot 9,6 \cdot 8)\end{array}$ & $\begin{array}{l}43 \\
51 \cdot 594 \\
7 \cdot 6 \\
(5 \cdot 5,10 \cdot 2)\end{array}$ & $\begin{array}{l}59 \\
50 \cdot 870 \\
10 \cdot 5 \\
(8 \cdot 1,13 \cdot 7)\end{array}$ & $\begin{array}{l}126 \\
150 \cdot 038 \\
7 \cdot 6 \\
(6 \cdot 4,9 \cdot 1)\end{array}$ & $\begin{array}{l}7 \cdot 3 \\
(6 \cdot 1,8 \cdot 8)\end{array}$ \\
\hline $\begin{array}{l}\text { Girls } \\
\text { Cases (no) } \\
\text { Population } \\
\text { Incidence rate } \\
(95 \% \mathrm{CI})\end{array}$ & $\begin{array}{l}16 \\
44 \cdot 610 \\
3 \cdot 3 \\
1 \cdot 9,5 \cdot 3\end{array}$ & $\begin{array}{l}55 \\
48 \cdot 477 \\
10 \cdot 3 \\
7 \cdot 8,13 \cdot 5\end{array}$ & $\begin{array}{l}62 \\
47 \cdot 500 \\
11 \cdot 9 \\
9 \cdot 2,15 \cdot 4\end{array}$ & $\begin{array}{l}133 \\
140 \cdot 587 \\
8 \cdot 6 \\
7 \cdot 2,10 \cdot 2\end{array}$ & $\begin{array}{l}8 \cdot 1 \\
(6 \cdot 8,9 \cdot 7)\end{array}$ \\
\hline $\begin{array}{l}\text { Total } \\
\text { Cases (no) } \\
\text { Population } \\
\text { Incidence rate } \\
(95 \% \text { CI })\end{array}$ & $\begin{array}{l}40 \\
92 \cdot 184 \\
3 \cdot 9 \\
2 \cdot 8,5 \cdot 3\end{array}$ & $\begin{array}{l}98 \\
100 \cdot 071 \\
8 \cdot 9 \\
7 \cdot 3,10 \cdot 9\end{array}$ & $\begin{array}{l}121 \\
98 \cdot 370 \\
11 \cdot 2 \\
9 \cdot 3,13 \cdot 4\end{array}$ & $\begin{array}{l}259 \\
290 \cdot 625 \\
8 \cdot 1 \\
7 \cdot 1,9 \cdot 2\end{array}$ & $\begin{array}{l}7 \cdot 7 \\
6 \cdot 8,8 \cdot 7\end{array}$ \\
\hline
\end{tabular}

for girls, and $7 \cdot 7$ for both sexes. The highest incidence was in the age group $10-14$ years. The overall male:female ratio was 0.90 (table).

There was a year to year fluctuation in both crude incidence and estimated incidence (crude rate/completeness of ascertainment), with two peaks, one in 1985 and the other surrounding the year 1991 .

The largest numbers of new cases were identified in the months of January and September, and the smallest numbers in April, May, and June. The seasonal pattern in the total material was significantly different from a uniform distribution of new cases throughout the year $(p<0.01)$. The mean number of new cases in the winter months, December, January and February, was significantly different from the yearly mean $(p<0.05)$.

Discussion: The IDDM incidence rate of 7.7 per 100000 in Belgrade compares with rates in European countries with low-medium incidence. This rate is comparable to those in France, Hungary, Austria, and northern Italy; is higher than that in Israel; and is lower than rates in Nordic countries, in Denmark, and the United Kingdom. ${ }^{3}$ In Belgrade, however, the IDDM incidence is higher than that during the years 1989 and 1990 in Bucharest, ${ }^{3}$ which is on a latitude close to that of Belgrade. It is also higher than the rates in Slovenia and Poland, ${ }^{3}$ which are further north. There are other examples which are inconsistent with a north to south gradient. ${ }^{3}$ Taking into account year to year fluctuation and epidemic type variation in IDDM incidence, however, a north to south gradient can not be discussed on the basis of one or two year incidence rates, especially when small variations in latitude and rates of incidence are concerned. The rates in Sardinia and Iceland ${ }^{3}$ could be regarded as exceptions.

Our data confirm earlier findings that there is often a slight female preponderance in low incidence populations.

A trend of increasing incidence for childhood 
diabetes has been observed both in Europe and elsewhere. ${ }^{4}$ Our study period of 11 years was too short to provide an accurate analysis of any time trend in incidence. In fact, there seemed to be a non-linear, epidemic type variation, with a possible outbreak in 1985 and around the year 1991. It has recently been pointed out that IDDM is a rather atypical chronic disease in that its "epidemics" are evident and relatively common. ${ }^{5}$

In our study a typical seasonal variation in incidence was established.

Since the pathological process leading to IDDM may start years before the clinical onset, the epidemic variation, as well as the seasonal one, probably reflects the activity of triggering factors rather than aetiological factors.

Funded by the Ministry of Science and Technology in Serbia through the contract no 8774, 1991-95.

1 WHO study group. Diabetes mellitus. Geneva: WHO, 1985 9-20. Technical Report Series No 727.

2 Cochi SL, Edmonds LE, Dyer $\mathrm{K}$ et al. Congenital rubella syndrome in the United States, 1970-1985: on the verge of elimination. Am 7 Epidemiol 1989;129:349-61.

3 Green A, Gale EAM, Patterson CC for the EURODIAB ACE Study Group. Incidence of childhood-onset insulin ACE Study Group. Incidence of childhood-onset insulindependent diabetes mellit

4 Bingley PJ, Gale EAM. Rising incidence of IDDM in Europe. Diabetes Care 1989;12:289-95.

5 World Health Organisation DIAMOND Project Group on Epidemics. Childhood diabetes, epidemics, and epidemiology: An approach for controlling diabetes. $\mathrm{Am} \mathcal{f}$ Epidemiol 1992;135:803-16.

\title{
Alcohol consumption and obesity in the adult population of Spain
}

\author{
Juan L Gutiérrez-Fisac, Fernando Rodríguez-Artalejo, Carmen Rodríguez-Blas, \\ Juan del Rey-Calero
}

Although diverse research has shown that alcoholics tend to have lower body weights, the relationship between alcohol consumption and adiposity in the general population has not been well established: studies have yielded varied and inconsistent results, reporting positive, negative, or no clear associations. ${ }^{1}$ We examined the relationship between regular drinking, including the consumption of different kinds of alcohol, and obesity in the Mediterranean population of Spain.

Methods: We studied 10645 men and 11193 women aged 20-64 years interviewed in the Spanish national health survey carried out in $1987 .{ }^{2}$ Obesity was determined by calculating the Quetelet index (QI) (defined as weight $(\mathrm{kg}) / \mathrm{height}\left(\mathrm{m}^{2}\right)$ ) using self reported weight and height. Subjects were considered obese if their QI was $\geqslant 85$ th centile for age group and gender.

Alcohol consumption was measured by a quantity-frequency index adapted to the pattern of alcoholic beverage consumption in Spain. Information was gathered on the usual frequency of consumption and the quantity consumed for each type of beverage studied during the year before the interview. Subjects were classified by alcohol consumption in accordance with previous studies. ${ }^{3}$ The proportions in each drinking category were: $36.9 \%$ non-drinkers, $49.5 \%$ moderate drinkers, $6.9 \%$ heavy drinkers, and $4.9 \%$ excessive drinkers. To measure the association between alcohol consumption and obesity, we calculated the odds ratios (OR) for men and women using non-conditional logistic regression. ${ }^{4}$ Several variables were taken into account because of their potential confounding effect: age, education, size of community, smoking, leisure time physical activity, consumption of any med- ication for hypertension and heart conditions over the previous two weeks, and, current weight loss diet or any other special diet. We checked for the presence of a dose-response relationship by carrying out a weighted linear regression analysis of the ORs.

Results: The crude and adjusted ORs for obesity for different types of alcoholic drinks and at different levels of consumption in Spanish men and women are shown in the table. For total alcohol intake, the adjusted OR in men increases between occasional drinkers and excessive drinkers, from 0.92 to $1 \cdot 17$. This positive tendency was statistically significant $(p=0.011)$. In women, the observed effect was just the reverse, ORs $<1$ that decreased significantly as the amount of alcohol consumption rose were seen. This trend was also statistically significant $(\mathrm{p}<0.001)$.

With regard to wine, the ORs tend to be $>1$, especially in heavy and excessive drinkers, suggesting a positive association. The most important association for wine consumption and obesity was observed in women; their adjusted OR was substantial (1.75) in excessive drinkers and statistically significant in heavy drinkers $(1.46,95 \% \mathrm{CI}=1.05,2.03)$ who showed a dose-response relationship that was close to statistical significance $(p=0 \cdot 066)$.

Discussion: This paper describes the relationship between regular alcohol consumption and obesity in the Spanish population. Findings for men and women are opposed - that is, there is a weak positive association in men and a weak negative association in women. Other studies on the same subject have provided similar results. ${ }^{5}$ The negative relationship detected in women is one of 